\title{
Waxing and Waning of Observed Extreme Annual Tropical Rainfall
}

\author{
Jai Sukhatme and V. Venugopal \\ Centre for Atmospheric and Oceanic Sciences \& Divecha Centre for Climate Change, \\ Indian Institute of Science, Bangalore 560012, India.
}

(Dated: October 9, 2018)

\begin{abstract}
We begin by providing observational evidence that the probability of encountering very high and very low annual tropical rainfall has increased significantly in the recent decade (1998-present) as compared to the preceding warming era (1979-1997). These changes over land and ocean are spatially coherent and comprise of a rearrangement of very wet regions and a systematic expansion of dry zones. While the increased likelihood of extremes is consistent with a higher average temperature during the pause (as compared to 1979-1997), it is important to note that the periods considered are also characterized by a transition from a relatively warm to cold phase of the El Niño Southern Oscillation (ENSO). To further probe the relation between contrasting phases of ENSO and extremes in accumulation, a similar comparison is performed between 1960-1978 (another extended cold phase of ENSO) and the aforementioned warming era. Though limited by land-only observations, in this cold-to-warm transition, remarkably, a near-exact reversal of extremes is noted both statistically and geographically. This is despite the average temperature being higher in 1979-1997 as compared to 1960-1978. Taken together, we propose that there is a fundamental mode of natural variability, involving the waxing and waning of extremes in accumulation of global tropical rainfall with different phases of ENSO.
\end{abstract}

Journal Ref: QJRMS, DOI:10.1002/qj.2633, 2015.

\section{INTRODUCTION}

In the context of global warming, the increasing moisture content of the troposphere [23, 48] is expected to result in an amplification of short-duration extreme rainfall events [5, 37, 47], mostly validated by regional groundbased observations $[13,18,21]$. On longer timescales, a consequence of the increase in column integrated water vapour for locations with very high and low accumulation is the so-called thermodynamic effect of "wet regions getting wetter, and dry regions getting drier" [23, 53]. Some observations $[4,7,27]$ and long-term global warming simulations $[8,17,26,36]$ are consistent with the expected consequences of this paradigm. In addition, dynamical changes due to warming also affect rainfall [46]. The combination of these two complicate the precipitation response [6, 55], especially over land [19]. In fact, as suggested by [28, 29], the "wet-wetter, dry-drier" hypothesis may be more appropriate over land if the wet and dry regions are not considered to be fixed geographical locations [see also, 41].

Apart from the role of warming, it has been suggested that changes in regional extremes have a natural component. In particular, individual locations with more than a century long data clearly exhibit multiple cycles in heavy rainfall [see for example, 32, 54]. Further, it has been documented that regional extremes in rainfall vary with El Niño and La Niña conditions [see 15, 20, 25, 51, for reports on the continental United States, South America, eastern Australia and the Philippines, respectively]. In fact, connections between daily and monthly extremes and the El Niño Southern Oscillation (ENSO) on a more global scale have been explored over the tropical oceans $[3]$ as well as over land $[2,10,30]$. In addition to the effect of natural cycles on short-duration extremes, different regions in the tropics experience anomalously wet or dry years during El Niño and La Niña events [12, 42, 43].

Thus, short-duration regional rainfall extremes as well as very high and low annual accumulation are plausibly influenced by both warming and natural cycles. In the present work, we focus on the footprint of ENSO on annual accumulation and its extremes in the tropics. In Section 2, we compare extremes in global accumulation during the ongoing pause in global warming and the preceding warming era. Apart from the fact that the average temperature during the recent period since 1998 is higher than the preceding warming era, the warming-vs-pause contrast is also a comparison between long predominantly warm and cold phases of ENSO, respectively. Keeping this in mind, in Section 3, we attempt to delineate possible connections between these changes in very low and high annual rainfall and ENSO phase transitions. We also discuss, in Section 4, the consistency between our global viewpoint using annual rainfall as a measure, and the noted trends in short-duration regional extremes. Finally, the paper concludes with a summary of results and a brief discussion in Section 5 .

\section{WARMING VS PAUSE}

Observations suggest that, despite the continual buildup of greenhouse gases in the atmosphere, the rate of surface warming since 1998 has been slower than in the preceding decades $[9,14]$; a phenomenon referred to as the "pause" or "hiatus" in global warming. While the cause behind the ongoing hiatus has received much attention, 
with many competing theories in the fray, the answer remains elusive [see, for example, the succinct summary in 22]. Rather than worry about its cause, here we view the pause - the first of its kind with possibly others to follow [34] — as a natural laboratory wherein the climate continues to evolve with one its primary variables being held relatively constant. Given this unique state of affairs, the first question we ask concerns the fate of tropical rain during the pause as compared to the immediately preceding warming era [beginning in the late 1970s, 49].

With regard to rainfall measurements, the Global Precipitation Climatology Product (GPCP) provides data at a spatial and temporal resolution of 2.5 degrees and 1 month, respectively [1]. This data is available from 1979 to the present day, thus covering the hiatus and the preceding warming era. Due to its monthly temporal and coarse spatial resolution, short-duration localized intense precipitation events which are usually the focus of studies on extremes lie outside the scope of this data. Rather, the measure which we focus on in this work, which is arguably a better yardstick for assessing the "wet-wetter, dry-drier" paradigm, is annual accumulation at every grid point. Thus, in the remainder of this manuscript, extremes refer to very high and low annual accumulation.

We begin by examining the differences in annual tropical $(35 \mathrm{~S}-35 \mathrm{~N})$ rainfall accumulation as recorded in the hiatus (1998 to 2013) and the preceding warming era (1979 to 1997). Figure 1a shows the normalised frequency distributions of annual rainfall during these two periods. These distributions are based on the union of the data from every year of the respective era, i.e., a sample size of $19(16) \times 28 \times 72$. While frequency distributions are used for illustrating changes, cumulative distribution functions (CDF) are used for significance testing. Specifically, the Kolmogorov-Smirnov (KS) test [39] shows that the CDFs of accumulation have changed significantly between the two eras (a KS distance of 0.02 , leading to a $p$-value close to zero, based on the null hypothesis $H_{0}$ : $\left.\mathrm{CDF}_{\text {hiatus }}=\mathrm{CDF}_{\text {warming }}\right)$. The changes in the tails of the distributions are better captured in Figure 1b, which shows their difference (hiatus - warming). In particular, we note that, in the global tropics, the probabilities of encountering very low $(<200 \mathrm{~mm})$ and very high $(>$ $3000 \mathrm{~mm}$ ) accumulation have increased significantly during the hiatus. It is worth reiterating that in this comparison we are considering all the years that make up an era to be a single set, thus the increased probability of extremes in accumulation is true of the hiatus as a whole and individual years can deviate from this expectation.

In addition to the pause being warmer (on average) than the preceding warming era, the periods considered are also characterized by a transition from a relatively warm to cold phase of the ENSO [49]. This transition is evident when we examine the difference in rainfall climatology between the two eras (shown in Figure 2a). For (a)

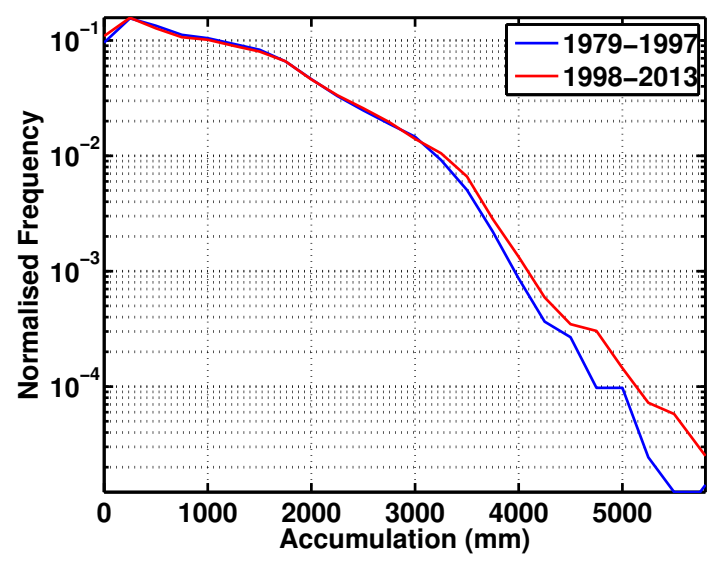

(b)

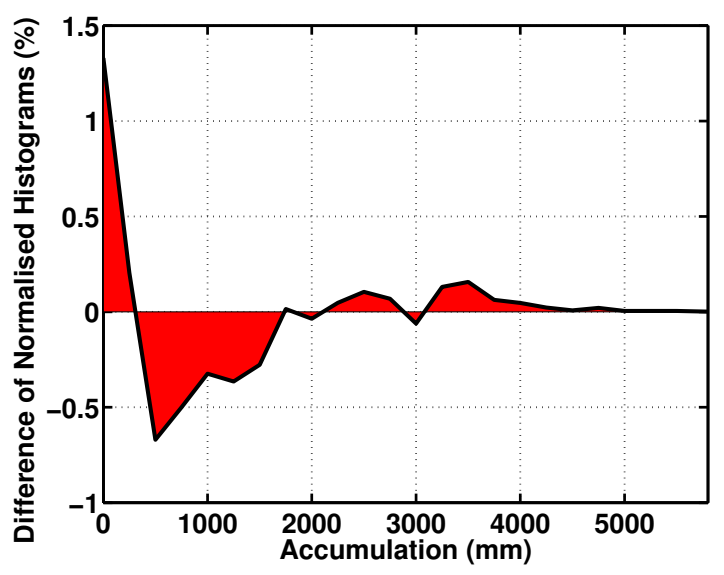

FIG. 1: (a) Normalised frequency histograms of the annual accumulation (mm) during 1979-1997 (blue) and 1998-2013 (red); and (b) Differences of these histograms. The frequencies shown are based on the union of the data from each of the two eras, i.e., sample sizes of $19(16$ years $) \times 28(35 \mathrm{~S}-35 \mathrm{~N}) \times$ 144 (0-360 longitude). The annual accumulation is based on 2.5-degree, monthly GPCP rainfall.

example, we see an east-west anomaly along the equatorial Pacific ocean, indicating a preference of moist convection more to the west (east) during the hiatus (warming). Similarly, the subtropical signature of the two phases can be seen with the southeastern spreading of anomalies into the southern Pacific Ocean [see, for example, 12, 42, 43, 52].

Thus, as both warming and a phase transition in ENSO are in play for the present comparison, it is not possible to attribute the noted increase in extremes of tropical accumulation to any one of these factors [see also the discussion in 40, for possible models of changes in rainfall distribution due to ENSO and warming]. To focus on the role of phase changes in ENSO on extreme accumulation, we note that the era preceding the late seventies, i.e., 1960 to the mid-1970s, was also a long 
(a)

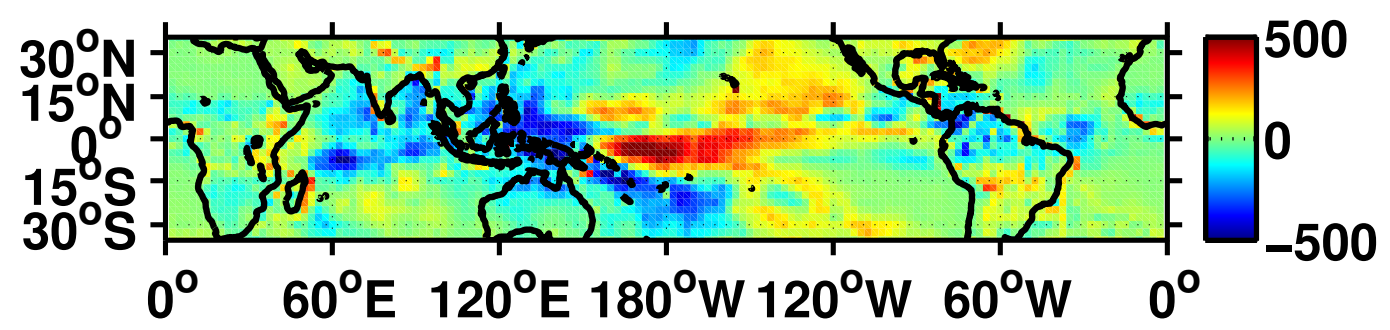

(b)

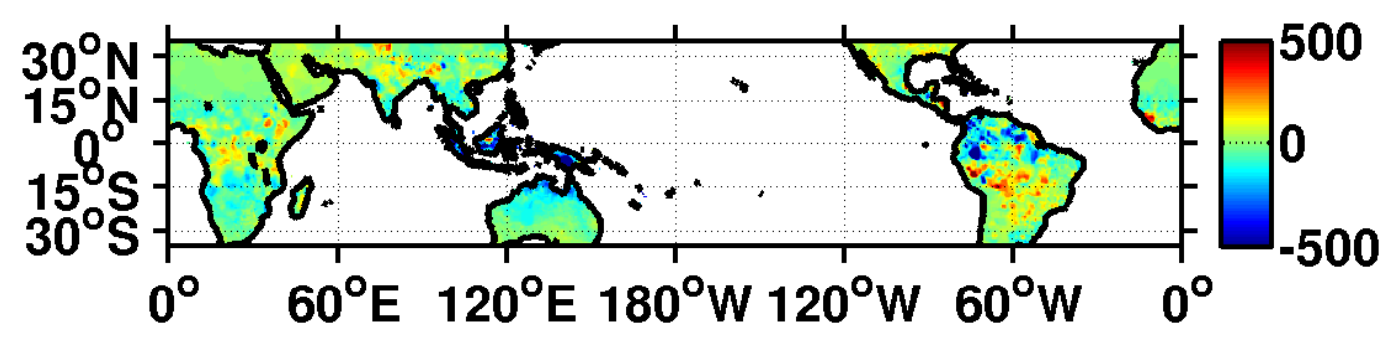

(c)

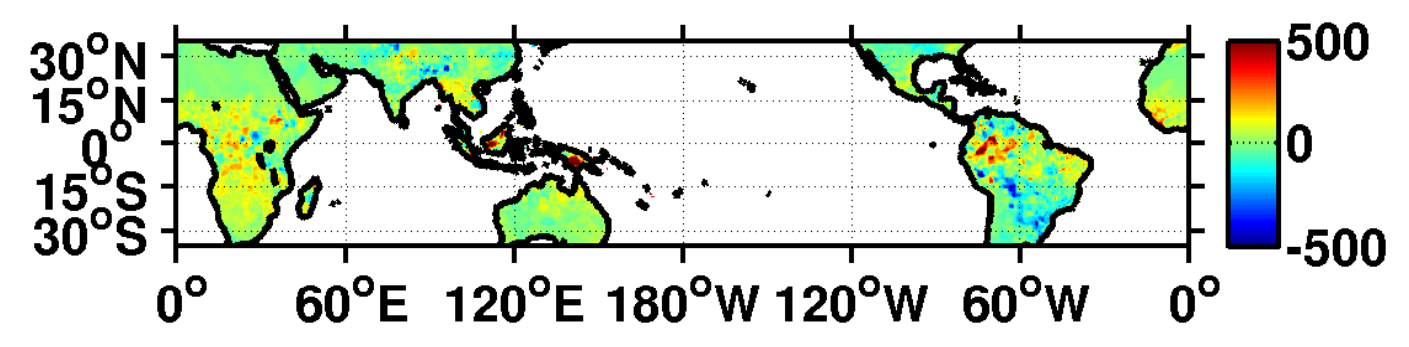

FIG. 2: (a) Spatial distribution of the difference of climatologies of annual accumulation (Warming - Pause; in mm), based on monthly, 2.5-degree, GPCP rainfall. (b) Same as (a), but over land using 0.5-degree, GPCC rainfall. (c) Same as (b), but between 1960-1978 and 1979-1997 (former - latter period).

cold phase of ENSO [see for example the discussion in 56]. In fact, both these transitions are also captured by the Pacific Decadal Oscillation index (see, for example, http://jisao.washington. edu/pdo). It should be kept in mind that a period identified as a particular phase of ENSO is interrupted by events of opposite polarity. For example, even though the pause is by and large a cold phase of ENSO, an examination of the PDO index reveals that the hiatus too can be partitioned into pre- and post-2005, where the latter period is dominated by La Niña conditions.

Given that there are no long-term tropical rainfall observations which cover both land and ocean, we utilise Global Precipitation Climatology Centre (GPCC) data [44], that is based on station observations (only land) and is available from 1950 onwards, at a spatial and temporal resolution of $0.5^{\circ}$ degree and 1 month, respectively. A difference in climatologies of annual accumulation for the two phase transitions of ENSO, namely, (i) \{1979-to$1997\}$ vs $\{1998$-to-2013\} (warm-to-cold) and (ii) $\{1960-$ to-1978\} vs $\{1979$-to-1997\} (cold-to-warm) are shown in Figure $2 \mathrm{~b}$ and $\mathrm{c}$, respectively. Not only are changes over land consistent between Figures $2 \mathrm{a}$ and b, they are also opposite in character to those shown in Figure 2c.

Having noted the expected changes in climatologies, the specific question we seek to answer is whether a coldto-warm transition is characterised by a decrease in extremes; i.e., is there a natural modulation of very high and low accumulation associated with ENSO phase transitions? In other words, given that the mean temperature during 1979-1997 was higher than the preceding era (1960s to the mid-1970s), if there is indeed a decrease in global extremes of accumulation, it clearly points to the role of ENSO phase transitions.

\section{EXTREMES AND ENSO TRANSITIONS}

Figure 3 shows the differences between the normalised histograms of accumulation, based on GPCC data, for two phase transitions of ENSO: (i) \{1979-to-1997\} - \{1960-to-1978 $\}$ and (ii) $\{1998$-to-2013 $\}-\{1979$-to$1997\}$. We note that the changes in very high and low 


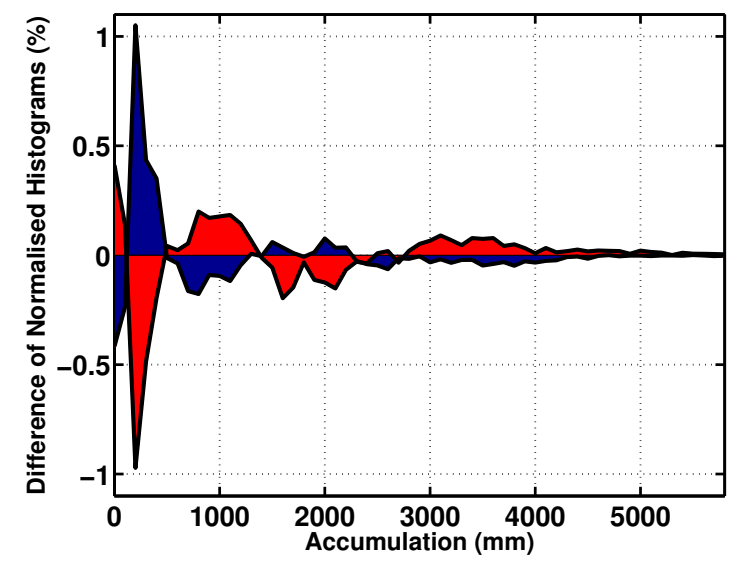

FIG. 3: Differences in the normalised histograms of the annual accumulation over land for two ENSO phase transitions, \{1979-to-1997\}-\{1960-to-1978\} (blue fill; cold to warm) and \{1998-to-2013\}-\{1979-to-1997\} (red fill; warm to cold). The estimates are based on GPCC 0.5-degree, monthly observations over land.

accumulation for the warm-to-cold transition from both GPCP (Figure 1b) and GPCC (red fill in Figure 3) are qualitatively similar. Further, even though land and ocean rainfall estimates from GPCP have different biases, the consistency with GPCC is reassuring. It is worth noting that the percentage changes in Figure 3 are smaller than in Figure 1b. This could be attributed to the higher spatial resolution of GPCC observations. More strikingly, the changes in extremes from a cold \{1960-to$1978\}$ to warm $\{1979$-to-1997\} phase of ENSO (blue fill in Figure 3) are exactly the opposite of what is observed in a warm-to-cold transition. This shows that relative changes in extremes of tropical accumulation are closely linked to ENSO.

To ascertain if there is a spatial character associated with the statistical changes described above, we utilize the crossings at approximately $200 \mathrm{~mm}$ and $3000 \mathrm{~mm}$ in Figures 1 and 3 as thresholds for very low ("dry") and high ("wet") accumulation, respectively. Further, the two eras that straddle a particular transition are denoted by E1 and E2 (where E2 follows E1 in time). Using this terminology, we construct "Index maps" that consist of a union of three sets. Specifically, these maps consist of geographical locations that accumulated more (less) than $3000 \mathrm{~mm}(200 \mathrm{~mm})$ of rain in (i) one or more of the years of E1 and E2 (cyan); (ii) one or more of the years of $\mathrm{E} 2$ and none of E1 (blue); (iii) one or more of the years of $\mathrm{E} 1$ and none of the years in E2 (red). Thus, locations in blue (red) represent appearance (disappearance) of wet and dry regions in E2 when compared to E1.

Consider first, the warm-to-cold transition, i.e., $\mathrm{E} 1=\{1979$-to- 1997$\}$ and $\mathrm{E} 2=\{1998$-to-2013 $\}$, which is captured by both GPCP and GPCC data. As seen from the global GPCP product (Figure 4), new high accumulation regions appear near the western maritime continent, over the Indian Ocean and the western part of equatorial
South America (blue in Figure 4a). This is accompanied by a depletion in the eastern core of the Pacific convergence zone (red). Overall, the "new" locations still lie within climatologically rainy zones, thus indicating a rearrangement of wet regions. The aforementioned changes over land are also seen from GPCC (blue in Figures 5a,b). At the other end, the new dry points take the form of spatially coherent fringes and indicate a systematic expansion of the existing dry regions off the western coasts of Australia, and North and South America (blue in Figure 4b). As this warm-to-cold transition also involves comparison with on-an-average warmer temperatures (during the pause), it is worth noting that the expansion of dry zones is sometimes linked to global warming [33][57]. Furthermore, on land (most clearly seen in Figure 5c from GPCC due to its higher spatial resolution), we observe a mixed signal over the Australian continent (red and blue), signs of new dry zones in the western United States and northern Pakistan (blue), along with the disappearance of existing dry regions in southern Africa and a coherent shrinking of the deserts in the Sahel region of northern Africa (red). It is worth noting that these changes over land are in very good agreement with regional reports; specifically, the projected drying of the western United States [2000 onwards; see 45], the occurrence of repeated severe droughts over northern Pakistan in the early 2000s[58], and the reduction of dryness over southern Africa [1998 onwards; see Figure 2 in 16] as well as the Sahel [38].

In the cold-to-warm transition (i.e., $\mathrm{E} 1=\{1960$-to$1978\}$ and $\mathrm{E} 2=\{1979$-to-1997 $\}$ ), which is only captured by GPCC data, the geographical changes (over land) seen in Figure 6 are almost exactly opposite in character to those in Figure 5. These changes are consistent with the reversal seen in the two ends of the probability distributions in Figure 3. In particular, the maritime continent shows a disappearance of wet points to the west (red), as does the western portion of equatorial South America (red). The same observation holds true for the very dry zones; here, new dry points are seen in southern Africa and the Sahel region (blue), while dryness reduces over Pakistan, western United States and much of continental Australia (red).

Thus, the answer to the question posed earlier (at the end of Section 2) is that, there appears to be an intrinsic waxing and waning, of very high and low tropical rainfall associated with ENSO phase transitions. Not only are the changes statistically significant, they also bear a coherent spatial signature.

\section{CONSISTENCY WITH TRENDS IN REGIONAL SHORT-DURATION EXTREMES}

Having taken a global point of view, with a focus on annual accumulation, we now assess whether the changes seen above agree with previously reported trends in re- 
(a)

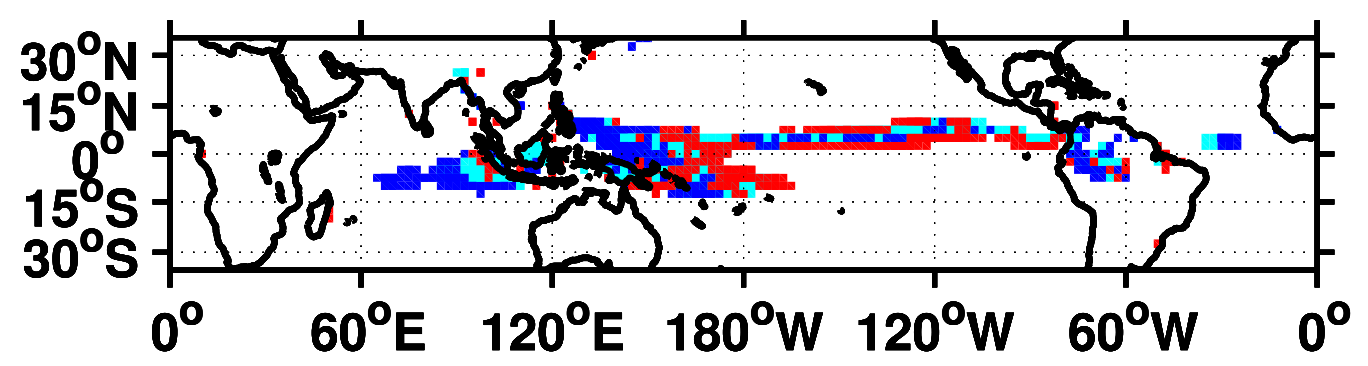

(b)

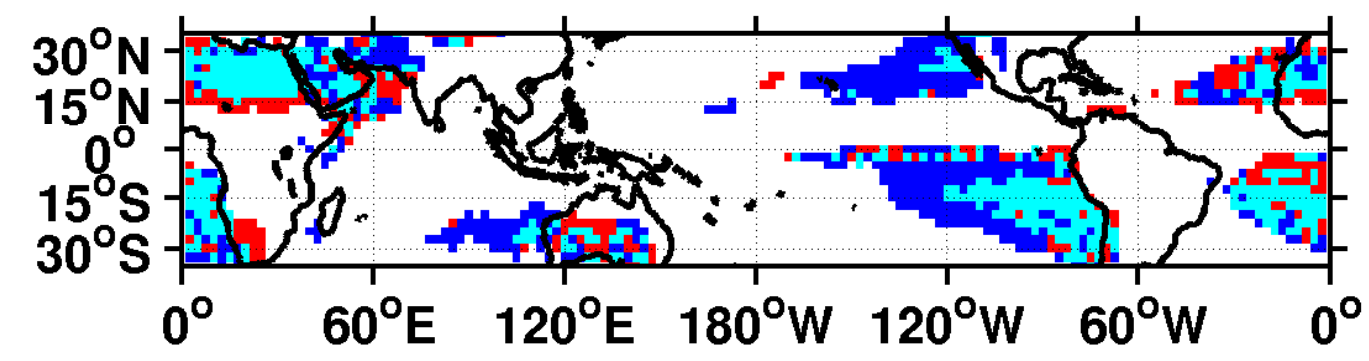

FIG. 4: Spatial distribution of the changes in the climatological (a) wet and (b) dry regions in the tropics, based on GPCP 2.5-degree, monthly observations. The colours shown represent those geographical locations that accumulated more (less) than $3000 \mathrm{~mm}(200 \mathrm{~mm})$ of rain (i) in one or more of the years of $\{1998$-to-2013\} and none of $\{1979$-to-1997\} (blue); (ii) in one or more of the years of $\{1979$-to-1997\} and none of the years in $\{1998$-to-2013\} (red); and (iii) in one or more of the years of both eras (cyan).

(a)

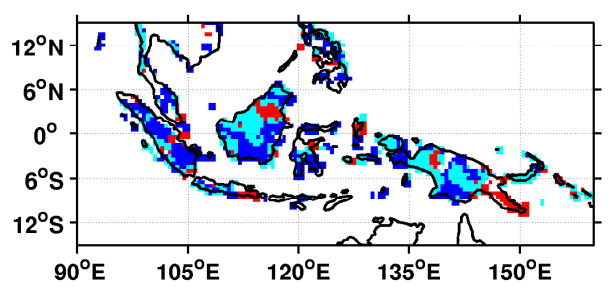

(b)
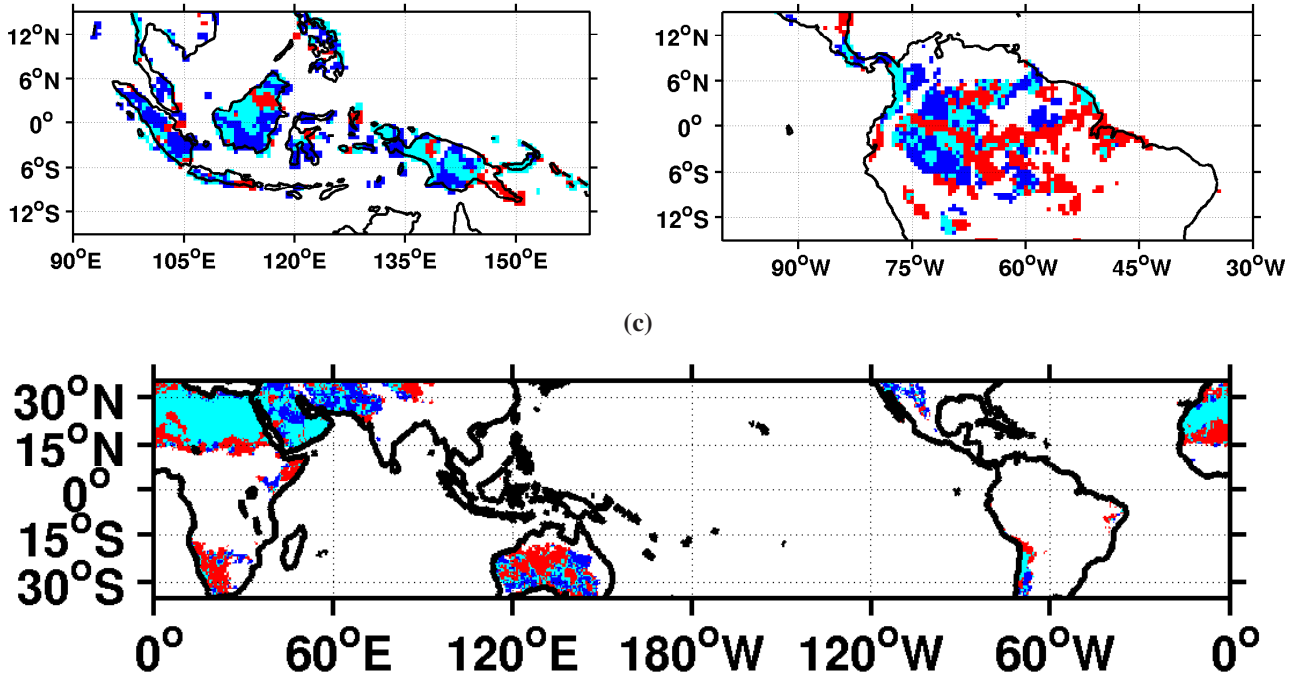

FIG. 5: Construction and color scheme same as Figure 4, but based on GPCC 0.5-degree, monthly land-only observations for the eras \{1979-to-1997\} and \{1998-to-2013\}. (a, b) Wet regions; (c) Dry regions. As before, blue/red represents appearance/disappearance of new wet/dry locations, and cyan represents no change.

gional extremes. Beginning with [24], there have been numerous reports of increasing trends in short-duration extreme rainfall events across the globe [see, for example, 13, 18, 21]. In order to show that this increase is in fact consistent with our global accumulation picture (waxing and waning), we use North America (15N-45N;
$60 \mathrm{~W}-130 \mathrm{~W})$ as an example. The motivation behind this choice stems from the fact that the region considered is large enough, so as to smooth out large local fluctuations, and thus more amenable to study extremes [see, for example, 21, and the references therein].

Following the same procedure as before, we construct 
(a)

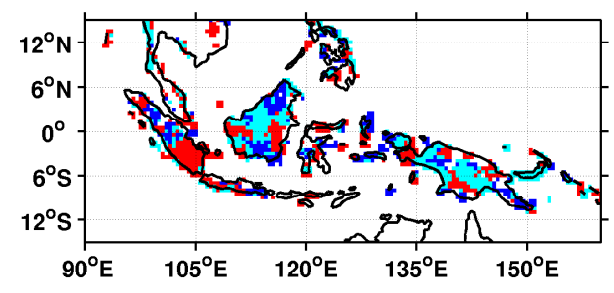

(b)

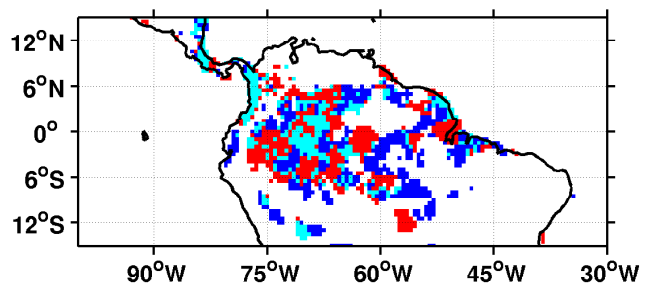

(c)

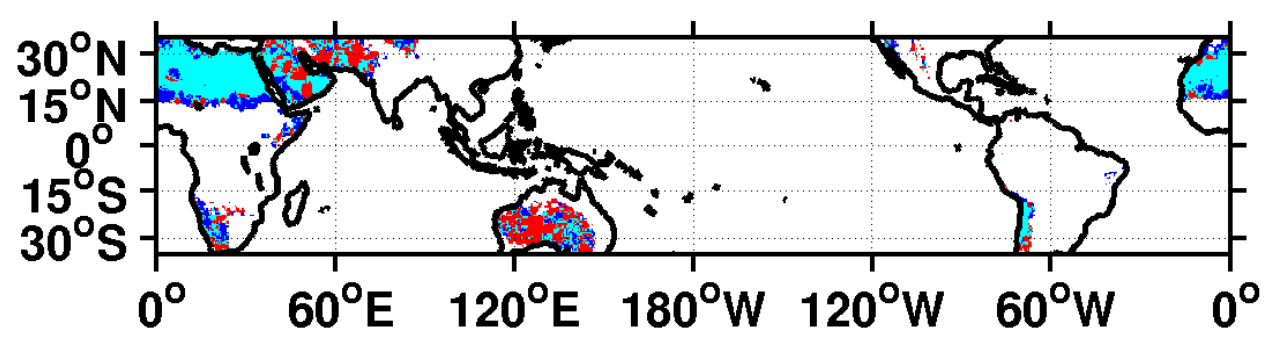

FIG. 6: Same as Figure 5, but for the eras $\{1960$-to-1978 $\}$ and $\{1979$-to-1997\}. (a, b) Wet regions; (c) Dry regions. As before, blue/red represents appearance/disappearance of new wet/dry locations, and cyan represents no change.

histograms and index maps for the two phase transitions over this region. The difference seen in the right tails of the histograms during the cold-to-warm transition (blue fill in Figure 7a) indicates an increased likelihood of exceeding annual rainfall of $\sim 1200 \mathrm{~mm}$. Indeed, this increase is marked by an appearance of new wet spots of high accumulation (blue in Figure 7b) in \{1979-to-1997\} as compared to $\{1960-$ to-1978\} over central US. This matches precisely with the significant short-duration extreme event trends from the mid 1970s to the late 1990s, over the contiguous central US, reported by [21]. Furthermore, as in the case of global tropics, the statistical and geographic changes associated with a warm-to-cold transition (Figure 7c) are opposite in nature to those during a cold-to-warm transition.

At first glance, in the cold-to-warm transition, the increase (decrease) in likelihood of encountering very high (low) annual rainfall over North America might appear to be contrary to the global tropical perspective presented earlier (i.e., waning of both wet and dry accumulation extremes; blue fill in Figure 3). A closer examination, however, indicates that this is not the case. In fact, the very high accumulation in the North American region forms a subset of the middle portion of the global histogram, and the changes between $\sim 1200 \mathrm{~mm}$ and $\sim 2000$ $\mathrm{mm}$ in Figures $7 \mathrm{a}$ and 3 are similar.

\section{DISCUSSION}

An immediate implication of our finding is that a warming signal can be enhanced or subdued depending on the phase of ENSO. However, disentangling their respective contributions to changes in rainfall extremes re- mains a challenge [e.g., 11]. That said, it is worth asking if our methodology can also shed light on the more gradual contribution of warming. To this end, a comparison of extremes in similar phases of ENSO could prove fruitful. Specifically, given the data at hand, we examined the changes in extreme accumulation in two cases: (i) between two temporally well-separated cold phases of ENSO (1960-1978 vs 1998-2013); and (ii) within the warming era that was mostly a warm phase of ENSO (1979-1987 vs 1988-1997). In both these cases, the average temperature is higher in the respective latter period. The first experiment (whose results can be deduced by summing the two curves in Figure 3) yields a marginal increase on the very wet side, and, in fact, a decrease in dry extremes, neither of which is statistically significant. The second experiment (differences in PDFs not shown) showed almost no change in extremes on either side; in fact, if anything, both very high and low accumulation showed a marginal decrease. Taken together, it is difficult to argue for a clear influence of warming on the extremes of annual accumulation; in fact, internal variability, as governed by the phases of ENSO, appears to play a much more significant role than warming.

To summarise, we studied the changes in very low and high tropical rainfall accumulation from a global point of view. The main finding is that there appears to be a fundamental natural mode of variability in tropical rainfall accumulation extremes with the changing phases of ENSO. Specifically, our analysis provides clear observational evidence that a warm-to-cold (cold-to-warm) transition of ENSO is associated with waxing (waning) of extreme accumulation, both statistically and spatially, over the global tropics. The dominant role of ENSO was made clear by comparing accumulation across two tran- 
sitions; specifically, cold-to-warm (1960-1978 vs 19791997) and a warm-to-cold (1979-1997 to 1998-2013), both of which involved a progressive increase in average global temperatures[59]. Moreover, as illustrated over the continental US, this global modulation is consistent with previously reported trends in short-duration regional extremes. support from the Divecha Centre for Climate Change. Discussions with George Huffman and John M. Wallace are greatly appreciated. We thank the Earth System Research Laboratory, NOAA for making available longterm GPCP and GPCC precipitation observations. We thank the two anonymous reviewers for their insightful and constructive comments.

Acknowledgements: JS \& VV acknowledge financial

[1] Adler RF et al. 2003. The Version-2 Global Precipitation Climatology Project (GPCP) monthly precipitation analysis (1979-Present). Journal of Hydrometeorology 4, 1147-1167.

[2] Alexander LV, Uotila P and Nicholls N. 2009. Influence of sea surface temperature variability on global temperature and precipitation extremes. Journal of Geophysical Research - Atmospheres 114, 10.1029/2009JD012301.

[3] Allan RP and Soden BJ. 2008. Atmospheric warming and the amplification of precipitation extremes. Science $\mathbf{3 2 1}$, DOI:10.1126/science.1160787.

[4] Allan RP, Soden BJ, John VO, Ingram W and Good P. 2010. Current changes in tropical precipitation. Environmental Research Letters 5, DOI:10.1088/17489326/5/2/025205.

[5] Allen MR and Ingram WJ. 2002. Constraints on future changes in climate and the hydrologic cycle. Nature $\mathbf{4 1 9}$, 224-232.

[6] Chadwick R, Boutle I and Martin G. 2013. Spatial Patterns of Precipitation Change in CMIP5: Why the Rich Do Not Get Richer in the Tropics. Journal of Climate 26, 3803-3822.

[7] Chou C, Chiang JCH, Lan C-W, Chung C-H, Lia Y$\mathrm{C}$ and Lee C-J. 2013. Increase in the range between wet and dry season precipitation. Nature Geoscience $\mathbf{6}$, DOI:10.1038/NGEO1744.

[8] Chou C, Neelin JD, Chen C-A and Tu J-Y. 2009. Evaluating the "Rich-Get-Richer" mechanism in tropical precipitation change under global warming. Journal of Climate 22, 1982-2005.

[9] Cowtan K and Way RG. 2014. Coverage bias in the HadCRUT4 temperature series and its impact on recent temperature trends. Quarterly Journal of the Royal Meteorological Society 140, 1935-1944.

[10] Curtis S, Salahuddin A, Adler RF, Huffman GJ, Gu G and Hong Y. 2007. Precipitation extremes estimated by GPCP and TRMM: ENSO relationships. Journal of Hydrometeorology 8, 678-689.

[11] DelSole T, Tippett MK and Shukla J. 2011. A significant component of unforced multidecadal variability in the recent acceleration of global warming. Journal of Climate 24, 909-926.

[12] Dai A and Wigley TML. 2000. Global patterns of ENSOinduced precipitation. Geophysical Research Letters 27, 1283-1286.

[13] Easterling DR, Evans JL, Groisman PYa, Karl TR, Kunkel KE and Ambenje P. 2000. Observed variability and trends in extreme climate events: A brief review. Bulletin of the American Meteorological Society 81, 417-
425.

[14] Fyfe JC, Gillet N and Zwiers F. 2013. Overestimated global warming over the past 20 years. Nature Climate Change 3, 767-769.

[15] Gershunov A and Cayan DR. 2003. Heavy daily precipitation frequency over the contiguous U.S. Sources of climatic variability and seasonal predictability. Journal of Climate 16, 2752-2765.

[16] Giannini A, Biasutti M, Held IM and Sobel AH. 2008. A global perspective on African climate. Climatic Change DOI:10.1007/s10584-008-9396-y.

[17] Giorgi F, Im E-S, Coppola E, Diffenbaugh NS, Gao XJ, Mariotti L and Shi Y. 2011. Higher hydroclimatic intensity with global warming. Journal of Climate 24, 53095324 .

[18] Goswami BN, Venugopal V, Sengupta D, Madhusoodanan M and Xavier PK. 2006. Increasing trend of extreme rain events over India in a warming environment. Science 314, DOI:10.1126/science.1132027.

[19] Greve P, Orlowsky B, Mueller B, Sheffield J, Reichstein M and Seneviratne SI. 2014. Global assessment of trends in wetting and drying over land. Nature Geoscience 7, 716-721.

[20] Grimm AM and Tedeschi RG. 2009. ENSO and extreme rainfall events in South America. Journal of Climate 22, 1589-1609.

[21] Groisman PYa, Knight RW, Easterling DR, Karl TR, Hegerl GC and Razuvaev VN. 2005. Trends in intense precipitation in the climate record. Journal of Climate 18, 1326-1350.

[22] Held IM. 2013. The cause of the pause. Nature 501, 318319.

[23] Held IM and Soden BJ. 2006. Robust responses of the hydrological cycle to global warming. Journal of Climate 19, 5686-5699.

[24] Iwashima T and Yamamoto R. 1993. A statistical analysis of the extreme events: Long-term trend of heavy daily precipitation. Journal of the Meteorological Society of Japan 71, 637-640.

[25] King AD, Alexander LV and Donat MG. 2013. Asymmetry in the response of eastern Australia extreme rainfall to low-frequency Pacific variability. Geophysical Research Letters 40, 2271-2277.

[26] Lau W.K-M., Wu H-T. and Kim K-M. 2013. A canonical response of precipitation characteristics to global warming from CMIP5 models. Geophysical Research Letters 40, 3163-3169.

[27] Liepert BG and Previdi M. 2009. Do models and observations disagree on the rainfall response to global warming? 
(a)

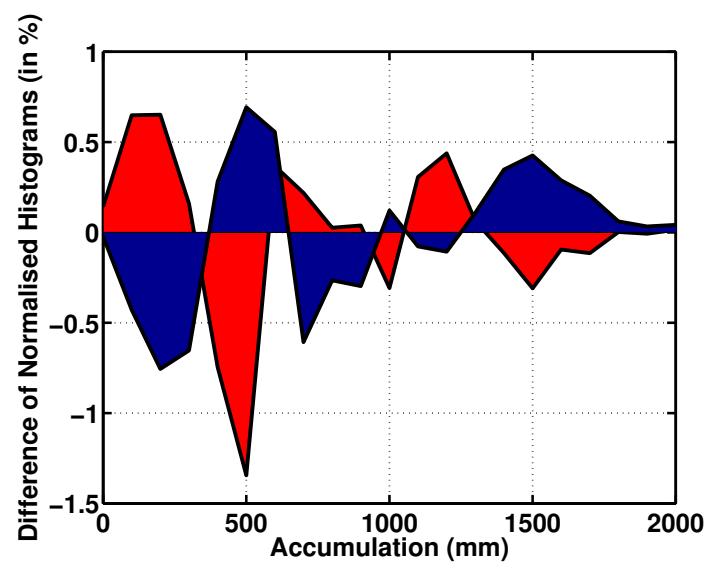

(b)

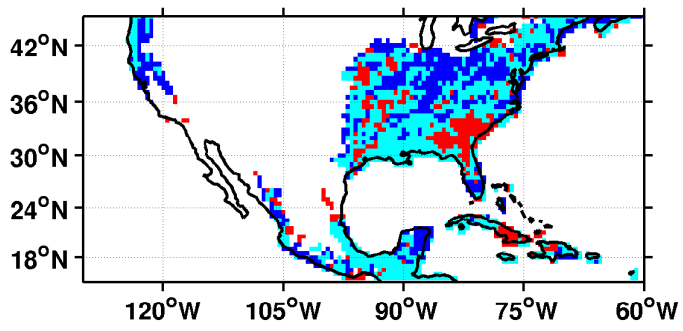

(c)

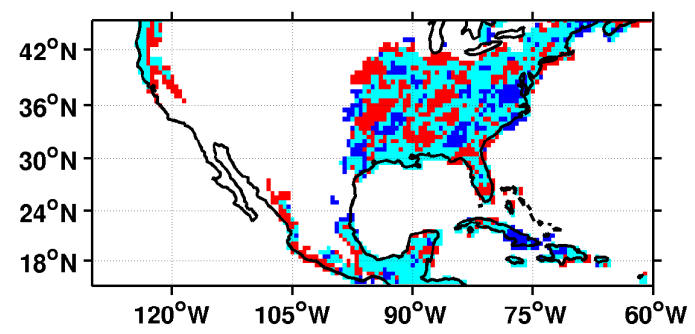

FIG. 7: (a) Same as Figure 3, but for North America (blue fill: cold-to-warm; red fill: warm-to-cold). Construction of the index map in the lower two panels is based on a threshold of $1200 \mathrm{~mm}$ or above, using GPCC land-only observations. The color scheme is the same as in Figure 6. (b) $\{1960$-to-1978\} and $\{1979$-to-1997\}; (c) $\{1979$-to-1997\} and \{1998-to-2013\}. As before, in panels (b) and (c), blue/red represents appearance/disappearance of new wet/dry locations, and cyan represents no change.

Journal of Climate 22, 3156-3166.

[28] Liu C and Allan RP. 2012. Multi-satellite observed responses of precipitation and its extremes to interannual climate variability. Journal of Geophysical Research 117, D03101.

[29] Liu C and Allan RP. 2013. Observed and simulated precipitation responses in wet and dry regions 1850-2100. Environmental Research Letters 8, 034002.

[30] Lyon B and Barnston AG. 2005. ENSO and the spatial extent of interannual precipitation extremes in tropical land areas. Journal of Climate 18, 5095-5109.

[31] Mantua NJ, Hare SR, Zhang Y and Wallace JM. 1997. A Pacific interdecadal climate oscillation with impacts on salmon production. Bulletin of the American Meteorological Society 78, 1069-1079.

[32] Marani M and Zanetti S. 2014. Long-term oscillations in rainfall extremes in a 268 year daily time series. Water
Resources Research 18, DOI:10.1002/2014WR015885.

[33] Marvel K and Bonfils C. 2013. Identifying external influences on global precipitation. Proceedings of the National Academy of Sciences 110, 19301-19306.

[34] Meehl GA, Arblaster J, Fasullo JT, Hu A and Trenberth KE. 2011. Model-based evidence of deep-ocean heat uptake during surface-temperature hiatus periods. Nature Climate Change 1, DOI:10.1038/NCLIMATE1229.

[35] Monteiro JM, Wallace JM, Sukhatme J and Murtugudde R. 2015. The contribution of ENSO variability to the recent expansion of the tropical belt. AGU Chapman Conference, Santa Fe, USA, July 2015.

[36] O'Gorman PA. 2012. Sensitivity of tropical precipitation extremes to climate change. Nature Geoscience 5, 697700.

[37] O'Gorman PA and Schneider T. 2009. The physical basis 
for increases in precipitation extremes in simulations of 21st-century climate change. Proceedings of the National Academy of Sciences 106, 14773-14777.

[38] Olsson L, Eklundh L and Ardö J. 2005. A recent greening of the Sahel-trends, patterns and potential causes. Journal of Arid Environments 63, 556-566.

[39] Papoulis A and Pillai U. 2002. Probability, Random variables and Stochastic Processes, McGraw Hill, 4th edition.

[40] Pendergrass AG and Hartmann DL. 2014. Two Modes of Change of the Distribution of Rain. Journal of Climate 27, 8357-8371.

[41] Polson D, Hegerl GC, Allan RP and Sarojini BB. 2013. Have greenhouse gases intensified the contrast between wet and dry regions? Geophysical Research Letters $\mathbf{4 0}$, DOI:10.1002/grl.50923.

[42] Ropelewski CF and Halpert MS. 1987. Global and Regional Scale Precipitation Patterns Associated with the El Niño/Southern Oscillation. Monthly Weather Review 115, 1606-1626.

[43] Ropelewski CF and Halpert MS. 1989. Precipitation patterns associated with the high index phase of the southern oscillation. Journal of Climate 2, 268-284.

[44] Schneider U, Becker A, Finger P, Meyer-Christoffer A, Ziese M and Rudolf B. 2013. GPCC's new land surface precipitation climatology based on quality-controlled in situ data and its role in quantifying the global water cycle. Theoretical and Applied Climatology 115, DOI:10.1007/s00704-013-0860-x.

[45] Seager R et al. 2007. Model projections of an imminent transition to a more arid climate in Southwestern North America. Science 316, DOI:10.1126/science.1139601.

[46] Seager R, Naik N and Vecchi GA. 2010. Thermodynamic and Dynamic Mechanisms for Large-Scale Changes in the Hydrological Cycle in Response to Global Warming. Journal of Climate 236, 4651-4668.

[47] Trenberth KE. 2009. Conceptual framework for changes of extremes of the hydrological cycle with climate change. Climate Change 42, 327-339.
[48] Trenberth KE. 2011. Changes in precipitation with climate change. Climate Research 47, 123-138.

[49] Trenberth KE and Fasullo JT. 2013. An apparent hiatus in global warming? Earth's Future 1, 19-32.

[50] Venugopal V and Sukhatme J 2015. Changes in tropical rainfall during the warming hiatus. in preparation.

[51] Villafuerte MQ et al. 2014. Long-term trends and variability of rainfall extremes in the Philippines. Atmospheric Research 137, 1-13.

[52] Wallace JM, Rasmussuon EM, Mitchell TP, Kousky VE, Sarachik ES and von Storch H. 1998. On the structure and evolution of ENSO-related climate variability in the tropical Pacific: Lessons from TOGA. Journal of Geophysical Research 103(C7), 14241-14259.

[53] Wentz FJ, Ricciardulli L, Hilburn K and Mears C. 2007. How much more rain will global warming bring? Science 317, 233-235.

[54] Willems P. 2013. Adjustment of extreme rainfall statistics accounting for multidecadal climate oscillations. Journal of Hydrology 490, 126-133.

[55] Xie S-P et al. 2010. Global Warming Pattern Formation: Sea Surface Temperature and Rainfall. Journal of Climate 23, 966-986.

[56] Zhang Y, Wallace JM and Battisti DM. 1997. ENSO-like interdecadal variability: 1900-93. Journal of Climate 10, 1004-1020.

[57] This expansion of dry zones is part of a developing story on the widening of tropical Hadley cells, which it itself appears to have a strong ENSO component [see, for example, 35].

[58] See for example the documentation of droughts over Pakistan, http://pakistanweatherportal.com/2011/ 05/08/history-of-drought-in-pakistan-in-detail.

[59] In fact, recent work compares accumulation within the pause (where temperatures are fairly uniform), and once again, an increase in extremes due to a warm-to-cold transition is clearly evident [50]. 